\title{
Exploration of donor effect on electron injection and photovoltaic properties of chalcone derivatives
}

\author{
AHMAD IRFAN ${ }^{1,2 *}$ \\ ${ }^{1}$ Research Center for Advanced Materials Science, King Khalid University, Abha 61413, P.O. Box 9004, Saudi Arabia \\ ${ }^{2}$ Department of Chemistry, Faculty of Science, King Khalid University, Abha 61413, P.O. Box 9004, Saudi Arabia
}

\begin{abstract}
Various photovoltaic parameters, i.e., electron injection $\left(\Delta \mathrm{G}^{\text {inject. }}\right)$, electronic coupling constants $\left(\left|\mathrm{V}_{\mathrm{RP}}\right|\right)$, light harvesting efficiencies (LHE), band alignment and electronic properties of five chalcone derivatives were studied by density functional theory (DFT) and time domain. The light was also shed on the effect of different electron donating groups and their strength intensity on the electronic and charge transfer properties. The balanced hole and electron reorganization energies for Comp 4 showed that it might have better ambipolar charge transfer in nature. The strong electron donating group(s) usually enhance(s) the $\Delta \mathrm{G}^{\text {inject. }}$ and $\left|\mathrm{V}_{\mathrm{RP}}\right|$ of chalcones as $-\mathrm{N}\left(\mathrm{CH}_{3}\right)_{2}>\mathrm{OCH}_{3}>\mathrm{OH}$. Additionally, $\Delta \mathrm{G}^{\text {inject. }}$ and $\left|\mathrm{V}_{\mathrm{RP}}\right|$ of various substituted chalcone derivatives have been observed as trimethoxy $>$ dimethoxy $>$ monomethoxy. The greater electron donating ability of substituents is also favorable for the staggered band alignment. The superior $\Delta \mathrm{G}^{\text {inject. }}$ of all the studied chalcones than of the referenced compounds disclosed that the prior compounds would be proficient photovoltaic materials.
\end{abstract}

Keywords: renewable energy; photovoltaic properties; density functional theory (DFT); band alignment; charge transfer properties; electron injection

\section{Introduction}

Chalcones have distinctive properties which make them suitable for sensors [1] and semiconducting devices such as organic light emitting diodes (OLEDs) [2], displays, thin film field effect transistors (TF-FET) [3], solar cells [4] and photo-reaction agents which can absorb energy in the form of light to initiate the reaction [5]. Today, improving the renewable energy is the foremost world problem [6]. Organic $\pi$-conjugated materials are of significant interest because of their low cost, tuning ability, structural diversity, favorable chemical modification, flexibility and ease of fabrication [7-11]. Nowadays, organic materials are usually used in dye-sensitized solar cells (DSSCs), organic solar cells, organic-inorganic hybrid solar cells (HSC), etc. Commonly, organic and inorganic parts are joined to achieve the gains of both

*E-mail: irfaahmad@gmail.com material groups [12]. The metal free compounds can develop efficiency, intramolecular charge transfer (ICT), stability, etc. [13, 14].

The huge light harvesting aptitude, conjugation between the donor and acceptor and electronic coupling strength positively affect the electron injection [15]. Moreover, thiophene based materials are favorable because of the semiconducting nature [16], non-linear optical behavior [17] and efficient electron transfer properties [18]. Previously, thiophene based heterocyclic chalcones showed improved properties [19].

Currently, five chalcones derivatives containing thiophene moiety were selected with the aim to investigate the electron injection, electronic coupling constants $\left(\left|\mathrm{V}_{\mathrm{RP}}\right|\right)$, light harvesting efficiencies (LHE), reorganization energies, electron affinities, energy level offset (ELO), band alignment with respect to $\mathrm{Si} / \mathrm{TiO}_{2}$ and phenyl-C61butyric acid methyl ester (PC61BM). The technical 
outcome of this manuscript is likely to have applications provoking experimentalists. To the best of our knowledge no such computational study has been carried out previously on these chalcones regarding their photovoltaic utilization. First time in the scientific community, we are going to explore these chalcone derivatives with respect to solar cell applications (Fig. 1).

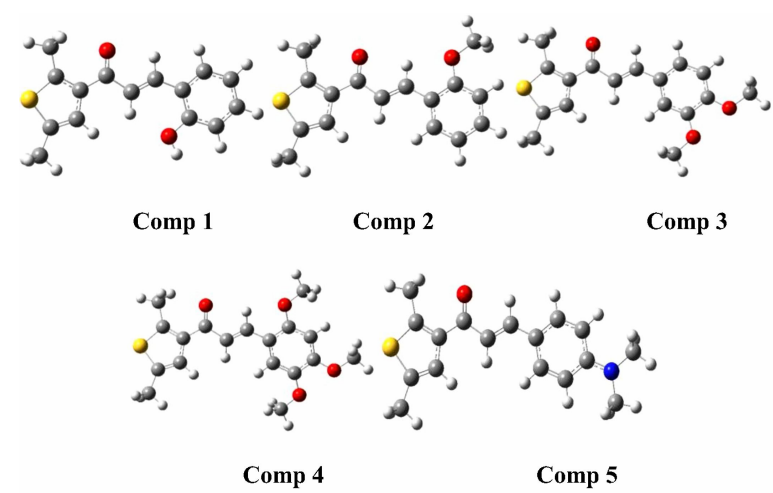

Fig. 1. Optimized structures of the chalcones at B3LYP/6-31G** level of theory (color scheme: $\mathrm{S}$ - yellow, $\mathrm{O}-$ red, $\mathrm{N}$ - blue, $\mathrm{C}$ - grey and $\mathrm{H}$ white).

\section{Computational details}

It has been shown that the B3LYP is the best choice among various DFT functionals which reproduce the electronic and optical properties of small molecules [20-22]. The electron injection was computed at B3LYP/6-31G** and time domain DFT (TD-B3LYP/6-31G**) level which has been found a rational method [23]. The geometries and charge transfer properties were calculated at B3LYP/6-31G** and TD-B3LYP/6-31G** level being an effective method [24]. Recently, it has been established that the calculated electronic and charge transfer properties of thiophene based materials at B3LYP/6-31G** level were in good agreement with the experimental evidences [25]. Moreover, various semiconducting properties were studied by using B3LYP/6-31G** and TD-B3LYP/6$31 \mathrm{G}^{* *}$ level [26, 27]. The electron injection mechanism was also studied at B3LYP/6-31G** level [28, 29]. Lately, the geometrical and electronic properties of the 2-cyano-5-(4-(phenyl(4vinylphenyl)amino)phenyl) penta-2,4-dienoic acid
(TC4) were computed at the B3LYP/6-31G** level [30]. Previously, the ground state $\left(\mathrm{S}_{0}\right)$ geometries, electronic and charge transfer properties of naphtho[2,3-b]thiophene and derivatives were studied at B3LYP/6-31G** and PBE0/6$31 G^{* *}$ level, where B3LYP/6-31G** level was found a reliable method [31]. In the present study, $\mathrm{S}_{0}$ geometries were optimized at DFT/B3LYP/6$31 \mathrm{G}^{* *}$ level. The $\left(\left|\mathrm{V}_{\mathrm{RP}}\right|\right)$, reorganization energies and electron affinities were computed at the same level. The excitation energies and LHE of Comp 1-Comp 5 were computed by TDDFT [32] using TD-B3LYP/6-31G** level. All these calculations were carried out using Gaussian16 software. Computational details of the electron injection $\left(\Delta G^{\text {inject. }}\right),\left|V_{R P}\right|$, LHE and other charge transfer parameters can be found in the literature [28, 29].

\section{Results and discussion}

\subsection{Electron injection and electronic cou- pling constants}

The significant electron injection and other solar cell parameters which can help to understand the photovoltaic performance of chalcone derivatives were calculated at B3LYP/6-31G** and TD-B3LYP/6-31G** levels of theory. The computed $\Delta G^{\text {inject. }}, \mathrm{E}_{\mathrm{OX}}^{\text {dye }}, \mathrm{E}_{\mathrm{OX}}^{\text {dye } *}, \lambda_{\max }^{\mathrm{ICT}}, \mathrm{LHE},\left|\mathrm{V}_{\mathrm{RP}}\right|$ and $\Delta \mathrm{G}_{\mathrm{r}}^{\text {inject. }}$ are tabulated in Table 1 . The $\Delta \mathrm{G}^{\text {inject. }}$ and $\left|\mathrm{V}_{\mathrm{RP}}\right|$ of Dyenitro were calculated as -0.39 and 0.195 , respectively [33]. The $\Delta G^{\text {inject. }}$ of all the studied chalcone derivatives is greater than the Dyenitro. In Comp 1 , the $\Delta G^{\text {inject. }}\left(\left|V_{R P}\right|\right)$ for first and second excitations was observed as -1.74 (0.870) and $-1.97(0.985) \mathrm{eV}$, respectively. The $\Delta G^{\text {inject. }}$ of Comp 1 is 4.46 and 5.05 times higher than that of the reference compound for both the excitations. In Comp 2, the $\Delta G^{\text {inject. }}\left(\left|V_{R P}\right|\right)$ for first and second transitions was observed as $-1.76(0.880) \mathrm{eV}$ and $-1.89(0.945) \mathrm{eV}$, respectively. The $\Delta G^{\text {inject. }}\left(\left|V_{R P}\right|\right)$ for first and second transitions was found -2.00 (1.0) and -2.63 (1.315) eV in Comp 3, respectively. In Comp 4, the $\Delta \mathrm{G}^{\text {inject. }}\left(\left|\mathrm{V}_{R P}\right|\right)$ for first and second transitions was observed as -2.09 (1.045) and $-2.59(1.295) \mathrm{eV}$, 
respectively. In Comp 5, the $\Delta G^{\text {inject. }}\left(\left|V_{R P}\right|\right)$ for first and second transitions was observed as -2.23 (1.115) eV and -3.44 (1.720) eV, respectively.

The $\Delta \mathrm{G}^{\text {inject. }}$ of Comp 2 to Comp 5 was found to be 4.51 and $4.85,5.13$ and $6.74,5.36$ and 6.64, 5.72 and 8.83 times higher for first and second excitation than the reference compound, respectively. Moreover, the $\left|\mathrm{V}_{\mathrm{RP}}\right|$ of all the studied chalcone derivatives was also observed superior as compared to the Dyenitro.

It was expected that $-\mathrm{OCH}_{3}$ substitution at ortho-position in Comp 2 might lead to the $\Delta \mathrm{G}^{\text {inject. }}$ and $\left|V_{R P}\right|$ greater than the Comp 1 but the results showed that $\Delta G^{\text {inject. }}$ and $\left|V_{R P}\right|$ of Comp 1 is 0.20 times higher than that of Comp 2. However, it can be seen that the $\Delta \mathrm{G}^{\text {inject. }}$ and $\left|\mathrm{V}_{\mathrm{RP}}\right|$ are almost the same. In Comp 1 the $-\mathrm{OH}$ group is at ortho position (i.e., trans to keto group) whilst in Comp 2 the $-\mathrm{OCH}_{3}$ group at ortho position (i.e. cis to keto group) reveals that the strength of EDG is not only single parameter here to boost the electron injection ability but the substituted position would also play a vital role. The di-methoxy in Comp 3 further enhances the donor strength as compared to Comp 2 thus increasing the $\Delta G^{\text {inject. }}$ and $\left|V_{R P}\right|$ values. Similarly, the tri-methoxy in Comp 4 auxiliary develops the donating power, resulting in enhancement of the electron injection and coupling constant values as compared to the Comp 2 and Comp 3. Likewise, the $-\left(\mathrm{CH}_{3}\right) \mathrm{N}$ in Comp 5 improves the donating power resulting in enhancing the electron injection and coupling constant values as compared to Comp 1 to Comp 4.

The main transitions in the absorption wavelengths of Comp 1 to Comp 5 are $\mathrm{H} \rightarrow \mathrm{L}$. The second transitions for Comp 1, Comp 2 and Comp 4 are H-1 $\rightarrow$ L, while for Comp 3 and Comp 5 are $\mathrm{H}-3 \rightarrow$ L. At the ground state, the HOMO-1 and HOMO of Comp 1 are delocalized on the entire structure of the molecule while the LUMO is distributed at 3-(2-hydroxyphenyl)prop2-en-1-one unit. The comprehensible ICT was perceived from HOMO-1/HOMO of thiophene to the 3-(2-hydroxyphenyl)prop-2-en-1-one. In Comp 5, the HOMO and LUMO are mainly found on the phenyl-prop-2-en-1-one and amino group while the HOMO-3, at the thiophene and keto oxygen. A noteworthy ICT was seen from thiophene to the phenyl-prop-2-en-1-one.

Here, the $\Delta G^{\text {inject. }}$ and $\left|V_{R P}\right|$ of chalcone derivatives have been compared with some previously studied hydrazone, triphenylamine, triaminopyrazolo[1,5-a]pyrimidine based dyes.

The triphenylamine TC4_system3 showed $\Delta \mathrm{G}^{\text {inject. }}$ and $\left|\mathrm{V}_{\mathrm{RP}}\right|-2.0 \mathrm{eV}$ and $1.0 \mathrm{eV}$ at TD-BH and HLYP/6-311+G**//B3LYP/6-31G** level [34] while 3b_TPA $-2.49 \mathrm{eV}$ and $1.24 \mathrm{eV}$ at TD-CAM-B3LYP/6-31G**//B3LYP/6-31G** level of theory, respectively [35]. The $\Delta G^{\text {inject. }}$ and $\left|\mathrm{V}_{\mathrm{RP}}\right|$ for azo dye (4b) was found -1.19 and $0.53 \mathrm{eV}$ at TD-B3LYP/6-31G*//B3LYP/6-31G* level, respectively [36]. The $\Delta G^{\text {inject. }}$ and $\left|V_{R P}\right|$ of hydrazone dye (system 5) were observed as -0.61 and $0.305 \mathrm{eV}$ at TD-B3LYP/6-31G*//B3LYP/6$31 G^{*}$ level, respectively [33]. The $\Delta G^{\text {inject. }}$ of triphenylamine of 2TPA-R was found -1.16 and $-2.46 \mathrm{eV}$ for first and second excited states, respectively [37]. In present study, the $\Delta \mathrm{G}^{\text {inject. }}$ and $\left|V_{R P}\right|$ of chalcone derivatives Comp 3 to Comp 5 are greater than the above mentioned referenced compounds; illuminating these studied compounds might be proficient sensitizers.

\subsection{Band gap alignment}

Previously, Pan [38] showed that to improve the solar energy harvesting and to develop electronic and optical properties as well as carrier mobility, staggered band alignment is important. Besides, he also showed that superior solar cell efficiency is largely based on staggered band alignment that can lead to electron-hole separation and light-absorption. Here, we have demonstrated the band alignment of the studied compounds with respect to $\mathrm{TiO}_{2}$ cluster and $\mathrm{Si}$ (Fig. 2).

In this work, the HOMO and LUMO energies of $\mathrm{Si}$ were considered as $-5.43 \mathrm{eV}$ and $-3.92 \mathrm{eV}$ [39], while for $\mathrm{TiO}_{2}$ as $-7.40 \mathrm{eV}$ and $-4.20 \mathrm{eV}$, respectively [40]. Previously, HOMO energies were calculated at B3LYP/6-31G** level, i.e. $-5.89,-5.81,-5.50,-5.15$ and 5.12 , while LUMO energies $-1.78,-1.82,-1.75,-1.61$ and 
Table 1. The $\Delta \mathrm{G}^{\text {inject. }}, \Delta \mathrm{G}_{\mathrm{r}}^{\text {inject. }}$, oxidation potential, light harvesting efficiency (LHE), $\left|\mathrm{V}_{\mathrm{RP}}\right|$ of investigated dyes at TD-B3LYP/6-31G** level of theory.

\begin{tabular}{lccccccccc}
\hline System & $\begin{array}{c}\Delta \mathrm{G}^{\text {inject. }} \\
{[\mathrm{eV}]}\end{array}$ & $\begin{array}{c}\mathrm{E}_{\mathrm{OX}}^{\text {dye }} \\
{[\mathrm{eV}]}\end{array}$ & $\begin{array}{c}\mathrm{E}_{\mathrm{OX}}^{\text {dye* }} \\
{[\mathrm{eV}]}\end{array}$ & $\begin{array}{c}\lambda_{\max }^{\mathrm{ICT}} \\
{[\mathrm{eV}]}\end{array}$ & transition & $\mathrm{f}$ & LHE & $\begin{array}{c}\Delta \mathrm{G}_{\mathrm{r}}^{\text {inject. }} \\
{[\mathrm{eV}]}\end{array}$ & $\begin{array}{c}\left|\mathrm{V}_{\mathrm{RP}}\right| \\
{[\mathrm{eV}]}\end{array}$ \\
\hline \hline a Dyenitro & -0.39 & 5.96 & 3.61 & 2.35 & $\mathrm{H} \rightarrow \mathrm{L}$ & 1.3189 & 0.9520 & 1.00 & 0.195 \\
& -1.74 & 5.89 & 2.26 & 3.62 & $\mathrm{H} \rightarrow \mathrm{L}$ & 0.181 & 0.2169 & 4.46 & 0.870 \\
Comp 1 & -1.97 & 5.89 & 2.03 & 3.86 & $\mathrm{H}-1 \rightarrow \mathrm{L}$ & 0.367 & 0.2984 & 5.05 & 0.985 \\
& -1.76 & 5.81 & 2.24 & 3.57 & $\mathrm{H} \rightarrow \mathrm{L}$ & 0.397 & 0.0907 & 4.51 & 0.880 \\
Comp 2 & -1.89 & 5.81 & 2.11 & 3.70 & $\mathrm{H}-1 \rightarrow \mathrm{L}$ & 0.164 & 0.2835 & 4.85 & 0.945 \\
& -2.00 & 5.50 & 2.00 & 3.50 & $\mathrm{H} \rightarrow \mathrm{L}$ & 0.716 & 0.2284 & 5.13 & 1.000 \\
Comp 3 & -2.63 & 5.50 & 1.37 & 4.13 & $\mathrm{H}-3 \rightarrow \mathrm{L}$ & 0.177 & 0.3320 & 6.74 & 1.315 \\
& -2.09 & 5.15 & 1.91 & 3.24 & $\mathrm{H} \rightarrow \mathrm{L}$ & 0.462 & 0.1003 & 5.36 & 1.045 \\
Comp 4 & -2.59 & 5.15 & 1.41 & 3.74 & $\mathrm{H}-1 \rightarrow \mathrm{L}$ & 0.033 & 0.3130 & 6.64 & 1.295 \\
& -2.23 & 5.12 & 1.77 & 3.35 & $\mathrm{H} \rightarrow \mathrm{L}$ & 0.921 & 0.2294 & 5.72 & 1.115 \\
Comp 5 & -3.44 & 5.12 & 0.56 & 4.56 & $\mathrm{H}-3 \rightarrow \mathrm{L}$ & 0.188 & 0.3040 & 8.83 & 1.720 \\
& & & & & & & & &
\end{tabular}

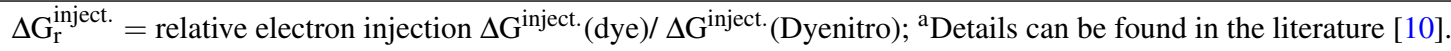

-1.56 for Comp 1 to Comp 5, respectively. The HOMO energy levels of Comp 1 to Comp 3 are lower while the LUMO energy levels are higher than the HOMO and LUMO of Si, respectively. The straddling gap alignment was observed by considering Comp 1 to Comp 3 as donor moiety, while $\mathrm{Si}$ as acceptor. On other hand, the HOMO and LUMO energy levels of the Comp 4 and Comp 5 are higher than the HOMO and LUMO energy levels of $\mathrm{Si}$, respectively. The staggered gap alignment was perceived by considering Comp 4 and Comp 5 as donor whereas $\mathrm{Si}$ as acceptor. The average valence and conduction band energies are $-6.41 \mathrm{eV}$ and $-4.06 \mathrm{eV}$ for $\mathrm{Si}$ and $\mathrm{TiO}_{2}$. It can also be seen that $\mathrm{Si} / \mathrm{TiO}_{2}$ as acceptor would change the straddling gap alignment to staggered gap alignment heterojunction, (Fig. 2). Previous studies showed that effective solar cell operation requires the staggered gap alignment heterojunction which distributes and transfers the holes to the anode and electrons to the cathode. Thus, it is expected that Comp 4 and Comp 5 might be good materials to be used in photovoltaic devices.

We have selected phenyl-C61-butyric acid methyl ester (PC61BM) as an acceptor which is widely used in organic solar cells. We have studied the band alignment of Comp 1 to Comp 5 with respect to PC61BM (Fig. 3). The electron

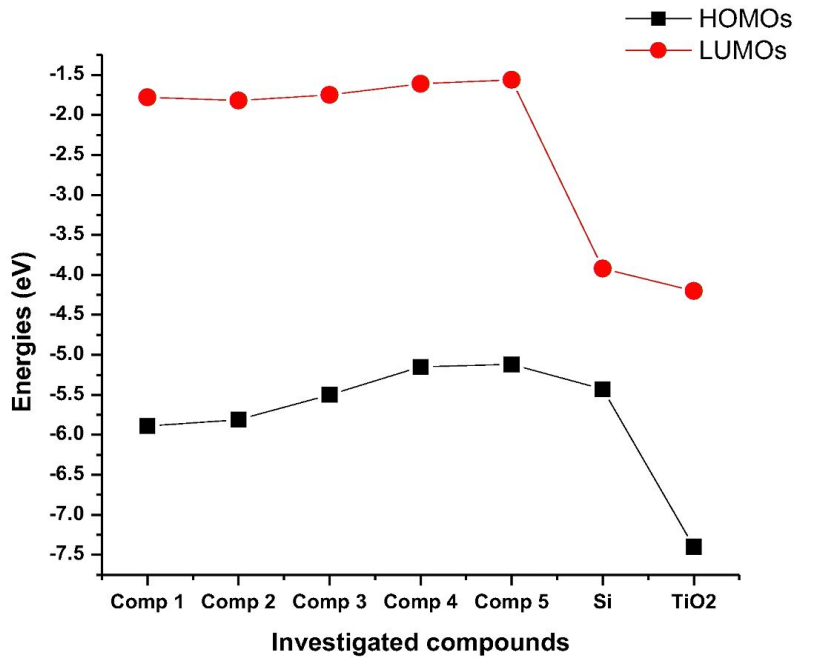

Fig. 2. The HOMOs and LUMOs energies of $\mathrm{Si}, \mathrm{TiO}_{2}$ and the Comp 1 to Comp 5.

donating strength usually changes the band alignment, e.g., mono-methoxy substituted derivatives do not show the staggered gap alignment. By increasing the electron donating strength, e.g. di-, tri-methoxy and dimethyl amine are favoring the staggered gap alignment. Interestingly in the case of Comp 3 to Comp 5 with respect to PC61BM, staggered gap alignment was observed enlightening that organic solar cell efficiency might be improved by using these compounds in OSC device. 


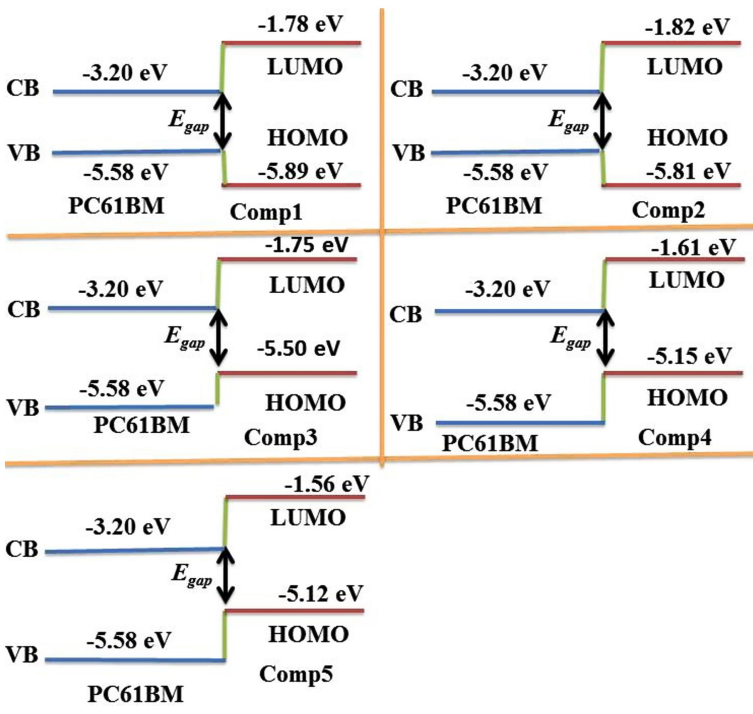

Fig. 3. Band alignment model of Comp 1 to Comp 5 with respect to PC61BM.

\subsection{Electronic properties}

In HSC, established excitons in a donor material are separated at the donor-acceptor (D-A) interface. The requisite force to overwhelm the exciton binding energy (EBE) is delivered by the ELO as LUMO of the donor and the conduction band edge of the acceptor material [41]. At B3LYP/6-31G** level, ELO for Comp 1 to Comp 5 was perceived as $2.28 \mathrm{eV}$, $2.24 \mathrm{eV}, 2.31 \mathrm{eV}, 2.45 \mathrm{eV}$, and $2.50 \mathrm{eV}$, respectively to overcome the EBE. For dissociation excitons made in the acceptor material, the ELO of the HOMO of the donor and the valence band edge of the acceptor material is requisite. Here, ELO was assessed as $0.52 \mathrm{eV}, 0.60 \mathrm{eV}, 0.91 \mathrm{eV}, 1.26 \mathrm{eV}$ and $1.29 \mathrm{eV}$ for Comp 1 to Comp 5, respectively, showing that less energy would be required for Comp 1 to Comp 3 to dissociate excitons. Scharber et al. [42] found that open-circuit voltage $\left(\mathrm{V}_{\mathrm{oc}}\right)$ is directly proportional to the diagonal band gap of HSC.

The short-circuit current density $\left(\mathrm{J}_{\mathrm{sc}}\right)$ is interrelated to the external quantum efficiency (EQE):

$$
E Q E=\eta_{a b s} \times \eta_{\text {diff }} \times \eta_{\text {diss }} \times \eta_{t r} \times \eta_{c c}
$$

The $\mathrm{J}_{\mathrm{sc}}$ is connected to the absorption yield $\left(\eta_{\text {abs }}\right)$. Thus, it is expected that organic compound and inorganic part $\mathrm{TiO}_{2} / \mathrm{Si}$ would enhance the absorption yield showing that combination of organic-inorganic hybrid materials can absorb energy in further solar spectrum region. Another, significant parameter is $\eta_{\text {diff }}$ which defines the exciton ability to diffuse to D-A interface [41]. The $\eta_{\text {diff }}$ is inversely proportional to the recombination rate within the photoactive material. $\eta_{\text {diss }}$ defines the exciton dissociation yield. Since the electron is bound within the exciton, the energy offset (EO) formed at the D-A interfaces is prerequisite force to discharge electron. To enable the charge transfer (CT), EO must be greater than the EBE [41]. In some previous studies the range for this energy was shown as $0.1 \mathrm{eV}$ to $0.5 \mathrm{eV}[43,44]$. In this study, EO is larger than the EBE showing that Comp 1 to Comp 5 would be good CT materials (Fig. 2).

The fourth parameter designates the efficiency of charge carrier transfer throughout the device $\left(\eta_{\text {tr }}\right)$. In organic compounds, CT ensues via hopping between energy states which are exaggerated by traps and recombination sites in the photoactive film. This CT attainment depends on the mobility of the accompanying semiconductors [45]. Likewise, Comp 1 to Comp 3 have the higher electron affinity than other contenders, revealing that in prior compounds electron transfer toward cathode might be superior.

The last key parameter $\eta_{\mathrm{cc}}$ pronounces the efficiency of charge collection at the electrodes. Previously, it has been shown that better hole injection into anode is possible if HOMO energy level of the donor material is greater than that of anode. It has been found that the HOMO energy levels of Comp 1 to Comp 5 are higher than that of the anode [46]. Brabec et al. [47] proposed an effective band gap model for HSC by correlating the maximum value of $\mathrm{V}_{\text {oc }}$ and the energy difference between the HOMO level of the donor and the LUMO level of the acceptor. In current study, we found diagonal band gap 1.83, 1.75, 1.44, 1.09 and $1.06 \mathrm{eV}$ of Comp 1 to Comp 5, respectively. Moreover, it is expected that higher electron affinity of Comp 1 to Comp 3 would escalate the $\mathrm{V}_{\text {oc }}$ eventual efficiency. 
The smaller hole reorganization energies of Comp 1, Comp 2, Comp 3 and Comp 5 than the electron ones show that these compounds might be better hole transfer materials. The balanced hole and electron reorganization energies of Comp 4 point out that this compound would be a good ambipolar material.

Table 2. The electron affinities, hole and electron reorganization energies of Comp 1 to Comp 5 calculated at B3LYP/6-31G** level of theory.

\begin{tabular}{lllll}
\hline Compounds & EAa & EAv & $\lambda(\mathrm{h})$ & $\lambda(\mathrm{e})$ \\
\hline \hline Comp 1 & 0.43 & 0.27 & 0.219 & 0.318 \\
Comp 2 & 0.52 & 0.33 & 0.232 & 0.397 \\
Comp 3 & 0.45 & 0.28 & 0.296 & 0.331 \\
Comp 4 & 0.39 & 0.18 & 0.405 & 0.409 \\
Comp 5 & 0.35 & 0.13 & 0.200 & 0.439 \\
\hline
\end{tabular}

\section{Conclusions}

The substitution of trimethoxy as well as $-\mathrm{N}\left(\mathrm{CH}_{3}\right)_{2}$ is good to enhance various photovoltaic parameters values. It is also expected that all the studied chalcone derivatives can be used as donor materials along with $\mathrm{Si} / \mathrm{TiO}_{2}$ as acceptor which establish staggered band alignment. The greater electron donating ability of di-, tri-methoxy and dimethylamine groups also favors the staggered band alignment with respect to Comp 3 to Comp 5 as donor and PC61BM as acceptor material. It can be also concluded that for the designing of better donor materials for organic solar cells, strong electron donating groups at various positions would be a good strategy. The calculated electron injection and electronic coupling constant values of Comp 1 to Comp 5 are greater than the referenced compounds. Also, their enhanced photovoltaic properties show that these compounds would be favorable for using in photovoltaic devices.

\section{Acknowledgements}

The author would like to express his gratitude to the Research Center for Advanced Materials Science, King Khalid University, Saudi Arabia, for support.

\section{References}

[1] Niu C.G., Guan A.L., Zeng G.M., LiU Y.G., LI Z.W., Anal. Chim. Acta., 577 (2006), 264.

[2] Makoto SATSUKi N.I., SADAharU Suga, Hisayoshi FujIKawa, Yasunori Taga, Organic light emitters using coumarin derivative as luminescent agents having efficiency and durability; display panels, in: US7252892 B2, 2007.

[3] ITAI Y., Thin film field effect transistor and display., US8188480 B2, in: 2012.

[4] Chambon S., D’ Aleo A., Baffert C., Wantz G., FAGES F., Chem. Commun., 49 (2013), 3555.

[5] PARK S.-H., Method of fabricating liquid crystal display device using a mixture of rubbing alignment material and UV alignment material. U.S.8654289, in: 2014.

[6] Goodenough JB A.H., Buchanan MV., Basic research needs for electrical energy storage, in: Report of the basic energy sciences workshop on electrical energy storage, DOEBES, 2007.

[7] Lan Y.-K., Huang C.-I., J. Phys. Chem. B, 112 (2008), 14857.

[8] Weitz R.T., Amsharov K., Zschieschang U., Villas E.B., Goswami D.K., Burghard M., Dosch H., Jansen M., Kern K., Klauk H., J. Am. Chem. Soc., 130 (2008), 4637.

[9] Newman C.R., Frisbie C.D., DA Silva Filho D.A., Brédas J.-L., EWBANK P.C., MANN K.R., Chem. Mater, 16 (2004), 4436.

[10] Zaumseil J., Sirringhaus H., Chem. Rev., 107 (2007), 1296.

[11] Chen H.-Y., Chao I., Chem. Phys. Lett., 401 (2005), 539.

[12] ZHOU Y., Eck M., Kruger M., Energ. Environ. Sci., 3 (2010), 1851.

[13] Irfan A., Chaudhry A.R., Jin R., Al-Sehemi A.G., Muhammad S., Tang S., J. Taiwan Inst. Chem. Eng., 80 (2017), 239.

[14] Irfan A., Chaudhry A.R., Muhammad S., ALSEHemi A.G., J. Mol. Graph. Model., 75 (2017), 209.

[15] Wiemer M., SABnis V., YUEN H., $43.5 \%$ efficient lattice matched solar cells, in: e.b.K.V. High and low concentrator systems for solar electric applications VI, Raed A. Sherif, P.o. SPIE (Eds.), 2011, pp. 810804.

[16] Irfan A., Cui R., Zhang J., Theor. Chem. Acc., 122 (2009), 275.

[17] Torruellas W.E., Neher D., Zanoni R., StegeMan G.I., Kajzar F., Leclerc M., Chem. Phys. Lett., 175 (1990), 11.

[18] Venkataraman L., Klare J.E., Nuckolls C., Hybertsen M.S., Steigerwald M.L., Nature, 442 (2006), 904. 
[19] Ki-Jun Hwang H.-S.K., In-CheOl Han, BeOMTAE KIM, Bull. Korean Chem. Soc., 33 (2012), 2585.

[20] SÁNCHEZ-CARrera R.S., COROPCEANU V., Silva Da F.D.A., Friedlein R., Osikowicz W., Murdey R., Suess C., Salaneck W.R., Brédas J.-L., J. Phys. Chem. B, 110 (2006), 18904.

[21] Irfan A., Muhammad S., Chaudhry A.R., AlSeHEMi A.G., Jin R., Optik, 149 (2017), 321.

[22] Guillaumont D., Nakamura S., Dyes Pigm., 46 (2000), 85.

[23] Jin R., IRFAN A., RSC Adv., 7 (2017), 39899.

[24] Zhang C., Liang W., Chen H., Chen Y., Wei Z., WU Y., J. Mol. Struct., 862 (2008), 98.

[25] Irfan A., Al-Sehemi A.G., Kalam A., J. Mol. Struct., 1049 (2013), 198.

[26] Irfan A., AL-Sehemi A.G., Chaudhry A.R., Muhammad S., Optik, 138 (2017), 349.

[27] Irfan A., Al-Sehemi A.G., Chaudhry A.R., Muhammad S., J. Saud. Uni.-Sci., https://doi. org/10.1016/j.jksus.2017.03.010 (2017).

[28] Preat J., Jacquemin D., Perpète E.A., Environ. Sci. Technol., 44 (2010), 5666.

[29] Preat J., Michaux C., Jacquemin D., Perpet̀e E.A., J. Phys. Chem. C, 113 (2009), 16821.

[30] Xu W., Peng B., Chen J., Liang M., Cai F., J. Phys. Chem. C, 112 (2008), 874.

[31] Huong V.T.T., Nguyen H.T., Tai T.B., Nguyen M.T., J. Phys. Chem. C, 117 (2013), 10175.

[32] Matthews D., Infelta P., Grätzel M., Sol. Energ. Mat. Sol. C., 44 (1996), 119.

[33] Al-Sehemi A., Irfan A., Asiri A., Theor. Chem. Acc., 131 (2012), 1.

[34] Irfan A., Al-Sehemi A., J. Mol. Model., 18 (2012), 4893.
[35] Irfan A., Jin R., AL-SEhemi A.G., Asiri A.M., Spectrochim. Acta A, 110 (2013), 60.

[36] Al-Sehemi A.G., Irfan A., Fouda A.M., Spectrochim. Acta A, 111 (2013), 223.

[37] Preat J., J. Phys. Chem. C, 114 (2010), 16716.

[38] PAN H., Renew. Sustain. Energ. Rev., 57 (2016), 584.

[39] Liu C.-Y., Holman Z.C., Kortshagen U.R., Nano Lett., 9 (2008), 449.

[40] Kuo C.Y., Tang W.C., Gau C., Guo T.F., Jeng D.Z., Appl. Phys. Lett., 93 (2008), 033307.

[41] Wright M., Uddin A., Sol. Energ. Mat. Sol. C., 107 (2012), 87.

[42] Scharber M.C., Mühlbacher D., Koppe M., Denk P., Waldauf C., Heeger A.J., Brabec C.J., Adv. Mater., 18 (2006), 789.

[43] Brabec C.J., Gowrisanker S., Halls J.J.M., LAird D., JiA S., Williams S.P., Adv. Mater, 22 (2010), 3839.

[44] Gregg B.A., Hanna M.C., J. Appl. Phys., 93 (2003), 3605.

[45] Mihailetchi V.D., Xie H.X., Boer de B., Koster L.J.A., BLom P.W.M., Adv. Funct. Mater., 16 (2006), 699.

[46] Irfan A., Al-Sehemi A.G., Al-Assiri M.S., J. Mol. Graph. Model., 44 (2013), 168.

[47] Brabec C.J., Cravino A., Meissner D., SariCIFTCI N.S., FromHERZ T., RISPENS M.T., Sanchez L., Hummelen J.C., Adv. Funct. Mater., 11 (2001), 374.

Received 2017-12-10 Accepted 2018-03-09 